\title{
Implementasi Kebijakan Ketahanan Pangan Dalam Meningkatkan Kesejahteraan Masyarakat di Kabupaten Pesisir Selatan
}

(studi kasus pengelolaan cadangan pangan pemerintahan desamelalui kelembagaan lumbung pangan)

Hasanatul Rahmi ${ }^{1}$, Dra. Jumiati, M.Si ${ }^{2}$

${ }^{1}$ Hasanatul, Padang, Indonesia,

2Jurusan Ilmu Administrasi Publik, Fakultas Ilmu Sosial, Universitas Negeri Padang,

Padang, Indonesia

${ }^{3}$ Email : hasanatulrahmi29@gmail.com ; jumiati.upik1962@gmail.com

\section{ABSTRAK}

The purpose of this study is to find out the implementation of food security policies to improve welfare through food reserve management programs. The aim is to increase the volume of group food reserves to ensure access and adequate food for its members and increase group capital through productive economic endeavors. This study uses qualitative research with a normativeempirical and phenomenal approach. The informants in this study were determined by purposive sampling with a total of 6 people, namely the Head of Planning, the Head of Food Security, the Mayor of Nagari and the Communitys. The data used are primary data and secondary data, derived from field observations or observations, interviews and documentation studies. This data is tested for validity using source triangulation techniques which are then analyzed with qualitative data analysis techniques. The results showed that the process of implementing food security policy in its implementation still needed some improvements such as in terms of resources involved, characteristics of the ruling institutions and responses from implementers. Supporting factors in the implementation of food security policies are built by the government food storage (granary) which is built by the special allocation fund (DAK) in agriculture and is given a budget in replenishing community food reserves. Whereas the saving factor is the lack of community understanding of how the system in managing community food reserves which causes internal problems in groups such as people who borrow grain / rice in storage (granaries) do not return loans according to the agreement. Efforts made by the Department of Food directly met with members of the group to request that loans be returned in accordance with the agreement that had been made so that the stock of community food reserves could still be available in storage areas (granaries).

Keywords :Implementation of food security policies, Public welfare, Food reserve management 


\section{PENDAHULUAN}

Kondisi terpenuhinya pangan bagi negara sampai dengan perorangan yang dapat tercermin dari tercukupinya ketersediaan pangan baik jumlah maupun mutunya, aman, beragam, bergisizi, merata serta terjangkau dan tidak bertentangan dengan agama, keyakinan dan budaya masyarakat, untuk dapat hidup sehat, aktif, dan produktif secara berkelanjutan (Undang-Undang Nomor 18 tahun 2012 tentang Pangan). Tidak tersedianya pangan dalam jumlah yang cukup serta mutu yang memadai dapat diartikan sebagai tidak sejahteranya kehidupan dan terjadinya kemiskinan.

Dalam rangka menciptakan ketahanan pangan untuk meningkatkan kesejahteraan masyarakat sesuai dengan amanat Undang-Undang No 18 Tahun 2012 tentang pangan di lakukan penjabaran dan rugulasi dari peraturan yang lebih merinci, dikeluarkannya Peraturan Pemerintah No 17 Tahun 2015 tentang Ketahanan Pangan dan Gizi sebagai penjabaran paraturan turunan dari UndangUndang Tentang Pangan.

Peraturan Pemerintah No 17 Tahun 2015 tentang Ketahanan Pangan dan Gizi, untuk menciptakan ketahanan pangan dan kesejahteraan masyarakat dilakukan kegiatan cadangan pangan pemerintahan desa/nagari yang dilakukan dengan produksi pangan poko tertentu diwilayah desa/nagari, kebutuhan untuk penanggulangan keadaan darurat dan kerawanan pangan di wilayah desa/nagari serta dilakukan sesuai dengan kebutuhan konsumsi masyarakat desa/nagari dan potensi sumber daya lokal.

Sementara itu untuk melakukan aksi tercapainya kebijakan ketahanan pangan, adanya program-program yang dalam meningkatkan kesejahtreraan masyarakat terhadap ketahanan pangan dengan dikeluarkannya Peraturan Menteri Pertanian No 17/Permentan/HK.140/4/2015 tentang Pedoman Pengembangan Lumbung Pangan Masyarakat.

Penyelenggaraan cadangan pangan pemerintahan desa dilakukan dengan pengembangan lumbung pangan, lumbung pangan dikelola oleh masyrakat di dalam sebuah desa/nagari yang cadangan pangan yang dikelola sesuai dengan kebutuhan masyarakat di desa/nagari untuk memenuhi kebutuhan masyrakat perseorangan sehari-hari.

\section{METODE PENELITIAN}

Penelitian ini merupakan penelitian kualitatif dengan menggunakan metode deskriptif. tujuannya untuk menggambarkan dan menjelaskan fenomena yang diamati secara langsung dan menghasilkan data deskriptif berupa kata-kata tertulis berbentuk naratif.(Sugiyono, 2012) 
Sumber data yang digunakan dalam penelitian ini menggunakan data primer dan sekunder, yang diambil langsung melalui proses wawancara dan observasi ke lapangan serta dari sumber bacaan dan berita. teknik untuk menguji keabsahann data yang dipakai dalam penelitian ini menggunakan triangulasi sumber, yakni mengecek data yang diperoleh melalui beberapa sumber. kemudian dianalisis dengan cara mereduksi data, penyajian data serta menarik kesimpulan.(Moleong, 2013)

\section{HASIL PENELITIAN DAN PEMBAHASAN}

\section{Implementasi Kebijakan Ketahanan pangan untuk Meningkatkan Ketahanan Pangan Masyarakat Kabupaten Pesisir Selatan}

Mengacu oada model implementasi yang dikemukakan oleh Grindel (dalam Header 2008) yang menyaakan bahwa keberhasilan implementasi suatu kebijakan ditentukan oleh dua aspek yaitu isi kebijakan (content of policy) dan lingkungan kebijakan (context of implementation).

\section{a. Aspek Isi Kebijakan}

2) Kepentingan kelompok sasaran

Kelompok sasaran dalam kebijakan ketahanan pangan ini adalah masyarakat petani yang tergabung dalam kelompok untuk mengelolaa cadangan pangan mereka sendiri. Kepentingan dari masayrakat ini adalah tercapainya keadilan akan terpenuhi kebutuhan pangan mereka sehari-hari dan terbabas dari kerwanan pangan agar tercapainya kehidupan yang sejahtera bagi masyarakat petani. Masyarakat petani juga akan dilakukan pemberdayaan agar memilki usaha ekonomi produktif yang dapat menambah pendapatan anggota kelompok. Usaha ekonomi produktif dilakukan dengan perputaran stok cadangan pangan kelompok itu bisa di jual kepada masyarakat umum yang nantinya keuntungan di bagi sama rata dengan anggota kelompok lain. Kemudian juga sistem tunda jual dimaksudkan apabila saat musim panen raya tiba namum harga gabah turun maka masyarakat dibina untuk menyimpan gabahnya terlebih dahulu di tempat penyimpanan (lumbung) yang pada saat harga gabah naik maka petani bisa menjual dan mendapatkan keuntungan yang lebih besar dari pada menjual gabah pada saat harga gabah turun.

3) Tipe manfaat

Dilihat dari isi kebijakan ketahanan pangan melalaui program pengelolaan cadangan pangan masyarakat dijelaskan bahwa dengan adanya kegiatan ini masyarakat petani mendapatkan bantuan pembangunan fisik tempat penyimpanan (lumbung) pangan yang diperuntukan kepada masyarakat petani agar dapat mengelola cadangan pangan mereka sendiri.Pengelolaan cadangan pangan masyarakat juga di fasilitasi dengan anggaran pengisian untuk mengisi stok cadangan pangan di dalam tempat penyimpanan (lumbung) yang diberikan oleh 
pemerintah.Pengelolaan cadangan panga masyarakat memilki manfaat unutuk meningkatkan volume cadangan pangan kelompok untuk menjamin akses dan kecukupan pangan bagi anggotanya dan meningkatkan modal kelompok melalui usaha ekonomi produktif di bidang pangan.

4) Derajat perubahan yang diinginkan

kebijakan ketahanan pangan melalui cadangan pangan bertujuan agar tercapainya keadilan akan kemudahan akses pangan bagi seluruh masyarakat. Dan kebijakan ini juga melakukan pembinaan dan pemebrian sosialisasi kepada masyarakat petani bahwa pada saat harga jual gabah turun sebaiknya dilakukan sistem tunda jual sampai terjadinya peningkatan harga gabah, agar masyarakat petani memilki keuntungan dan tidak dirugikan.

5) Pelaksanaan program

Dilihat dari Undang-Undang tentang pangan pelaksana kebijaka ketahanan pangan pemerintah provinsi menugaskan pemerintah daerah dan mengikut instansi lain dalam pengimplementasian kebijakan ini. Pemerintah Kabupaten Pesisir Selatan menugaskan dan memberikan wewenang kepada Dinas Pangan untuk menjalankan kebijakan dan mengawasi keberlangsungan kebijakan di dalam masyarakat.Pelaksana kebijakan haruslah yang memilki kompetensi, kualitas yang baik serta memahami maksud dan tujuan dari kebijakan ini.

6) Sumber daya yang dilibatkan

Dalam kebijakan ini sumber daya yang dilibatkan adalah pemerintahan nagari yang juga ikut berpartisipasi dalam mengawasi jalannya kebijakan ini di tingkat nagari, kemudian adanya sarana dan prasarana pembangunan tempat penyimpanan (lumbung) yang dibangun oleh pemerintah sebagai tempat penyimpanan stok cadangan pangan bagi masyarakat.Serta partisipasi dari masyarakat petani itu sendiri sebagai kelompok sasaran dalam kebijakan.

\section{b. Aspek Lingkungan}

1) Seberapa besar kekuasaan, kepentingan dan strategi yang dimiliki oleh para aktor yang terlibat dalam implementasi kebijakan

Dinas Pangan memilki strategi untuk mensosialisasikan kagiatan pengelolaan cadangan pangan ini dengan mengadakan penyuluhan mengenai kegiatan dan sosialisasi kepada masyarakat petani dan menjelaskan maksud dan tujuan program ini serta member tahu kepada masyarakat bagaimana sistem pengelolaan cadangan pangan masyarakat yang baik agar terjadinya kelancaran program dan keberlanjutan program.

2) Karakteristik lembaga penguasa 
Pemerintah daerah sebagai penyelenggara kebijakan di daerah bersama dinas pangan berkoordinasi dan bekerja sama dengan pemerintahan nagari dalam mengawasi jalannya kebijakan di dalam masyarakat.

3) Tingkat kepatuhan dan adanya respon dari pelaksana

Dalam implementasi kebijakan ketahanan pangan melalui program pengelolaan cadangan pangan masyarakat, Dinas Pangan sebagai pelaksana yang ditugaskan pemerintah daerah untuk mengawasi kebijakan telah menjalankan dan mematuhi isi-isi dari kebijakan tersebut, Dinas Pangan telah melakukan pendampingan dan memberikan sosialisasi serta telah mengakses anggaran untuk pelaksanaan program tersebut.

\section{Hambatan yang dihadapi dalam implementasi kebijakan ketahanan pangan dalam meningkatkan kesejahteraan masyarakat di Kabupaten Pesisir Selatan}

Berdasarkan beberapa kendala yang ditemui peneliti dilapangan dalam pelaksanaan implementasi kebijakan ketahananan pangan di kabupaten pesisir selatan berdasarkan teori yang diungkapkan oleh George C. Edward III yang mana ada 4 (empat) faktor yang mempengaruhi pelaksanaan kebijakan yaitu komunikasi, sumber daya, disposisi dan struktur organisasi, yang mana keempat faktor tersebut adalah :

\section{a. Komunikasi}

Berdasarkan hasil penelitian dilapangan menunjukkan bahwa kemampuan komunikasi organisasi pelaksana yakni Dinas Pangan dalam hal mengkomunikasikan pelaksanaan kebijakan kepada kelompok sasasaran belum berjalan dengan baik hal ini dapat terlihat dari masih adanya masyarakat yang belum memehami dengan jelas apa maksud dan tujuan akan pelaksanaan implementasi kebijakan ketahanan pangan tersebut.

b. Sumber daya

Pelaksanaan implementasi kebijakan akan kurang efektif apabila terdapat kendala kurangnya sumber daya di dalamnya. Hal ini dibuktikan dari kurangnya staf pendamping yang terjun kelapangan, monitoring lapangan yang jarang dilakukan serta kurangnya pengetahuan dan pemahaman anggota kelompok terhadap sistem pengelolaan program cadangan pangan tersebut.

\section{c. Disposisi}

Dinas pangan yang telah diberikan kekuasaan oleh pemerintah derah untuk dapat menjalankan dan mengawasi jalannya kebijakan di dalam masyarakat di anggap kurang memberikan respon yang cepat terhadap permasalahan yang 
dikeluhkan oleh anggota kelompok yang mengakibatkan masalah tidak teratasi bahkan berdampak pada ketidak berkelanjutan kebijakan tersebut

d. Struktur birokrasi

Salah satu aspek struktur yang penting dari standar setiap organisasi adanya standar operasional program (SOP) menjadi pedoman bagi setiap implementor dalam bertindak. Dan dari hasil penelitian menunjukkan bahwa strukrur organisasi yang terdapat di Dinas Pangan yang melaksanakan implementasi kebijakan ketahanan pangan telah sesuai dengan SOP yang ditetapkan untuk implementasi kebijakan ketahanan pangan.

3. Upaya yang dilakukan dalam mengatasi hambatan implementasi kebijakan ketahanan pangan dalam meningkatkan kesejahteraan masyarakat di Kabupaten Pesisir Selatan

Dalam mengatasi hambatan yang ditemui dilapangan dalam pelaksanaan implementasi kebijakan ketahanan pangan, Dinas Pangan sebagai penanggung jawab pelaksana implementasi kebijakan berupaya untuk mengtasi hambatan tersebut, upaya tersebut dilihat melalui aspek yang dikemukakan oleh George C. Edward yaitu komunikasi, sumber daya, disposisi dan struktur organisasi, sebagaimana dijelaskan sebagai berikut :

a. Kominikasi

Upaya yang dilakukan dinas pangan untuk meningkatkan komunikasi antara dinas pelaksana dan masyarakat adalah dengan mengadakan pertemuan kembali untuk pemberian sosialisasi mengenai pelaksanaan implementasi kebijakan yang akan dilakukan.

b. Sumber daya

Terjadinya kendala atas hak kepemilkan tanah, dinas pangan selaku penanggung jawab pelaksana implementasi kebijakan berkoordinasi dengan pemerintahan nagari setempat dengan menemui pemilki tanah agar pemilki tanah membiarkan menggunakan tanahnya untuk dibangun tempat cadangan pangan untuk masyarakat dan pemilki tanah pun di angkat menjadi ketua pengurus kelompok.

\section{c. Disposisi}

Upaya yang dilakukan untuk mengatasi kendala terhadap sikap dan respon pelaksana yang kurang tanggap, dinas pangan pangan selalu berupaya untuk dapat dengan cepat menanggapi permasalahan ataupun keluhan dilapangam, namun yang menjadi kendala adalah jarak di tiap-tiap lokasi yang mengakibatkan dinas pangan tidak dapat dengan rutin melakukan monitoring kelapangan dan menanggapi keluhan dari kelompok. 
d. Struktur birokrasi

Upaya yang dilakukan dalam struktur organisasi adalah dengan membentuk tim pelaksana implementasi kebijakan ketahanan pangan dengan, dengan adanya tim pendamping lapangan yang terjun kelapangan untuk memonitoring pelaksanaan dan jalannya implementasi kebijakan. pelaksanaan implementasi kebijakan telah di atur dan sesuai dengan standar operasional program (SOP) yang telah ditentukan.

\section{PENUTUP}

\section{A. Kesimpulan}

Berdasarkan hasil penelitian dan pembahasan yang dilakukan maka dapat diatarik kesimpulan yaitu :

1. Proses Implementasi kebijakan ketahanan pangan melalui pengelolaan cadangan pangan di atur dalam Peraturan Pemerintah No 17 tahun 2015 tentang Ketahanan pangan dan Gizi sebagai kebijakan turunan dari Undang-Undang No 18 Tahun 2012 tentang pangan yang menyatakan bahwa pemerintah dan pemerintah daerah melaksanakan implementasi kebijakan ketahanan pangan dan bertanggung jawab terhadap penyelenggaraan kebijakan ketahanan di wilayahnya masih-masing dengen memperhatikan pedoman, norma, standard dan kriteria yang ditetapkan pemerintah pusat. Implementasi kebijakan ketahanan pangan dalam meningkatkan kesejahteraan dilakukan dengan mempermudah masyarakat dalam hal ketersedian dan akses pangan bagi kebutuhan sehari-hari serta adanya pengembangan usaha ekonomi produktif yang dilakukan oleh masyarakat untuk menambah pendapatan serta tercapainya kesejahteraan bagi masyarakat petani. Namun hal tersebut belum mampu dikatakan dapat meningkatkan kesejahteraan masyarakat, karena dalam implementasinya masih ditemui hambatan-hambatan yang mengganggu pelaksanaan implementasi kebijakan.

2. Hambatandalam pelaksanaan kebijakan ketahanan pangan di Kabupaten pesisir selatan yaitu diliahat dari faktor komunikasi masih belum optimal antara Dinas Pangan maupun staff pendamping lapangan dengan anggota kelompok, sehingga masih adanya anggota kelompok yang belum memahami pelaksanaan implementasi kebijakan tersebut, dar segi sumber daya ini masih terjadinya permasalah terkait sarana dan prsarana yang digunakan. Permasalahan terkait sarana dan prsarana yaitu masalah penggunaan lahan untuk pembangunan tempat penyimpanan (lumbung) pangan dan ada permasalahan tidak dikembalikannya gabah yang dipinjam oleh anggota kelompok dari stok cadangan pangan.Kemudian dari segi faktor disposisi atau sikap pelaksana dalam merespon ataupun menaggapi permasalahan dilapangan yang masih kurang.

3. Upaya yang dilakukan untuk mengatasi permasalah yang timbul dalam implementasi kebijakan ketahanan pangan melalui pengelolaan cadangan pangan 
dalam wujud kelembagaan lumbung pangan, dari segi komunikasi masih adanya masyarakat yang belum memahami bagaimana pelaksanaan implementasi tersebut dinas pangan berupaya untuk memberikan kembali sosialisasi dan pemahaman yang jelas kepada anggota. Kemudian upaya untuk mengatasi hambatan dari segi sumber daya, permasalahn terkait sarana dan prasarana seperti permasalahan mengenai penggunaan lahan, Dinas Pangan dan pemerintahan nagari berkooridinasi dengan pemilk tanah agar mau menghibahkan tanahnya untuk dibangunya tempat penyimpanan (lumbung) pangan bagi masyarakat, yang pemilik tanah pun merangkap menjadi ketua pengurus cadanngan pangan masyarakat. Kemudian upaya yang dilakuakn untuk anggota yang meminjam gabah/beras namun tidak dikembalikan Dinas Pangan terjun langsung menenui anggota tersebut untuk mengingatkan bahwa apa yang dipijam dari penyimpanan (lumbung) cadangan pangan harus dikembalikan sesuai dengan kesepakatan yang telah ditentukan bersama-sama. Sedangkan upaya yang dilakukan dinas pangan untuk lebih merespon dengan cepat keluhan masyarakat, Dinas Pangan akan berupaya untuk lebih sering memonitoring atau terjun kelapangan untuk melihat bagaimana pelaksanaan implementasi kebijakan serta mendengar secara langsung keluhankeluhan dari anggota dilapangan.

\section{DAFTAR PUSTAKA}

Peraturan Pemerintah No 17 Tahun 2015 Tentang Ketahanan Pangan dan Gizi

Peraturan Menteri Pertanian No 17/Permentan/HK.140/4/2015 tentang Pedoman Pengembangan Lumbung Pangan Masyarakat.

Akib, H., \& Tarigan, A. (2008). Artikulasi Konsep Implementasi Kebijakan. Jurnal Baca, Vol. 1 A.

Dewan Ketahanan Pangan 2015. (n.d.). Kebijakan Strategis Pangan dan Gizi 2015-2019.

Moleong, L. (2013). Metode Penelitian Kualitatif (EdisiRevisi). Bandung: PT. Remaja Rosda karya.

Pemerintah Republik Indonesia. (2012). Undang-Undang Republik Indonesia Nomor 18 Tahun 2012 (pp. 1-25). pp. 1-25.

Sugiyono. (2012). Metode Penelitian Kuantitatif, Kualitatif, dan R\&D. Bandung: Alfabeta.

Suryati. (2014). Implementasi Kebijakan Ketahanan Pangan Daerah (Studi pada program peningkatan produksi beras nasional 9P2BN Kabupaten Kota Waringin Barat). Program Pasca Sarjana Universitas Terbuka.

Tajerin, T., Sastrawidjaja, S., \& Yusuf, R. (2017). TINGKAT KESEJAHTERAAN DAN KETAHANAN PANGAN RUMAHTANGGA NELAYAN MISKIN: Studi Kasus di 
Kelurahan Marunda Baru, DKI Jakarta dan Desa Tanjung Pasir, Banten. Jurnal Sosial Ekonomi Kelautan Dan Perikanan, 6(1), 83. https://doi.org/10.15578/jsekp.v6i1.5757

Wahab, S. A. (2014). Analisis Kebijakan dari Formulasi ke Penyusunan Model-Model Implementasi Kebijakan. Jakarta: Bumi Aksara. 